\title{
Thermal Conductivity of Aqueous Sugar Solutions under High Pressure
}

\author{
M. Werner • A. Baars • F. Werner - C. Eder • \\ A. Delgado
}

Published online: 25 October 2007

(C) Springer Science+Business Media, LLC 2007

\section{Erratum to: Int J Thermophys (2007) DOI 10.1007/s10765-007-0221-z}

The following is an addition to the article titled "Thermal Conductivity of Aqueous Sugar Solutions under High Pressure” by M. Werner, A. Baars, F. Werner, C. Eder, and A. Delgado that appears in this same issue of the International Journal of Thermophysics 28 (2007).

This work has been supported financially by the Deutsche Forschungsgemeinschaft (German Science Foundation) within the project DFG FOR 358/1-A3, the Bundesministerium für Bildung und Forschung (Federal Ministry of Education and Research) within the project 0330098A, and the Commission of the European Communities, Framework 6, Priority 5 'Food Quality and Safety', Integrated Project NovelQ FP6-CT-2006-015710.

The online version of the original article can be found under doi:10.1007/s10765-007-0221-z.

M. Werner $(\varangle) \cdot$ C. Eder

Lehrstuhl für Systemverfahrenstechnik, Technische Universität München,

Weihenstephaner Steig 23, 85350 Freising, Germany

e-mail: mwerner@wzw.tum.de

A. Baars

Hochschule Bremen,

28199 Bremen, Germany

F. Werner

Fachhochschule Weihenstephan, 85350 Freising, Germany

A. Delgado

Lehrstuhl für Strömungsmechanik, Friedrich-Alexander-Universität Erlangen-Nürnberg, 91058 Erlangen, Germany 